\title{
Post-traumatic Stress Symptoms in a Violently Injured Civilian Population: A Need for Hospital Identification and Resources
}

\author{
${ }^{1}$ Anne Jordan, ${ }^{2}$ Stephanie Goldberg, ${ }^{3}$ Julie Bivins, ${ }^{4}$ Bonita Hogue, ${ }^{5}$ Luke Wolfe, ${ }^{6}$ Michel B Aboutanos
}

\begin{abstract}
Background: Post-traumatic stress disorder (PTSD) has become a recognized healthcare crisis. Urban trauma centers (UTC) treat a high rate of violently injured patients, a known risk factor for PTSD. A quality improvement (QI) project related to PTSD was implemented to assess the prevalence of PTSD symptomology post-discharge and the need for inpatient screening and referral.
\end{abstract}

Study design: In 2013, 3,525 patients were admitted to a UTC, of which 560 suffered a violent injury. One hundred and twentysix $(23 \%)$ were provided PTSD education and offered resources for mental health treatment (MHT). Patients in police custody, with self-inflicted injuries, with injuries related to domestic violence, or who were non-English speaking were not included in the QI analysis (37\%). At 4 to 6 weeks post-discharge, patients were contacted and administered a four item PTSD screening tool. Referral to MHT was offered and provided if requested.

Results: One hundred and twenty-six patients were evaluated. Sixty-four (51\%) patients were reached at 4 to 6 weeks postdischarge and 60 (48\%) completed the full 4 -item tool. Fifty (78\%) had GSW, 7 (11\%) had stab wounds, and $7(11 \%)$ had assault. Sixty-two percent reported experiencing at least one major

\footnotetext{
${ }^{1}$ Assistant Director, Injury and Violence Prevention Program ${ }^{2}$ Assistant Professor of Surgery, ${ }^{3}$ Case Manager, Injury and Violence Prevention Program, ${ }^{4}$ Care Coordinator Manager Social Work, ${ }^{5}$ Assistant Professor, ${ }^{6}$ Professor of Surgery and Chief

${ }^{1-3}$ Division of Acute Care Surgical Services, Virginia Commonwealth University, Richmond, Virginia, United States

${ }^{4}$ Department of Care Coordination, Virginia Commonwealth University, Richmond, Virginia, United States

${ }^{5}$ Department of Surgery, Virginia Commonwealth University Richmond, Virginia, United States

${ }^{6}$ Division of Acute Care Surgery, Medical Director, VCU Trauma Center, Virginia Commonwealth University Medical Center East Broad Street Richmond, Virginia, United States

Corresponding Author: Michel B Aboutanos, Professor and Chief, Division of Acute Care Surgery, Medical Director VCU Trauma Center, Virginia Commonwealth University Medical Center, PO Box 980454, 1200 East Broad Street Richmond Virginia, United States, 23298-0454, Phone: 804 827-0043 e-mail: mbaboutanos@vcu.edu
}

symptom of PTSD, and $52 \%$ experienced $>2$ major symptoms. Eighty-seven percent of patients who developed symptoms of PTSD refused referrals pre-discharge. Post-discharge, patients with at least one PTSD symptom (37) requested MHT at a significantly higher rate than those without symptoms (23; $p=<0.0001$ ). Patients with 3 to 4 symptoms requested referral information at a higher rate than those with 0 to 2 symptoms $(p \leq 0.0001)$.

Conclusion: Violently injured patients are at risk for the development of PTSD symptoms post-discharge. Trauma centers have a unique opportunity to implement PTSD screening, referral and post-discharge follow-up to effect change for this at-risk population.

Keywords: Center of trauma, Mental health, Posttraumatic stress disorder, Prevalence, Violent injury.

How to cite this article: Jordan A, Goldberg S, Bivins J, Hogue B, Wolfe L, Aboutanos MB. Post-traumatic Stress Symptoms in a Violently Injured Civilian Population: A Need for Hospital Identification and Resources. Panam J Trauma Crit Care Emerg Surg 2015;4(2):54-58.

Source of support: Nil

Conflict of interest: None

\section{RESUMEN}

Antecedentes: El trastorno por estrés postraumático (PTSD) se ha convertido en una crisis de salud reconocida. Los Centros de trauma Urbanos (UTC) tratan a una alta tasa de pacientes heridos por violencia, un factor de riesgo conocido para el trastorno de estrés postraumático. Un proyecto de la mejora de la calidad (QI) relacionada a PTSD fue implementado para evaluar la prevalencia de la sintomatología del trastorno de estrés postraumático posterior a la aprobación de la gestión y la necesidad de detección de pacientes hospitalizados y referidos.

Diseño del estudio: En el 2013, 3.525 pacientes fueron ingresados en una UTC, de los cuales 560 sufrieron una lesión violenta. A ciento veintiséis (23\%) se proporcionó educación PTSD y se ofreció recursos para el tratamiento de salud mental (MHT). Los pacientes en custodia de la policía, con las lesiones auto infligidas, con heridas relacionadas a la violencia doméstica, o que no hablaban Inglés no se incluyeron en el análisis QI (37\%). A las 4 a 6 semanas después del alta, los pacientes fueron contactados y se administró una herramienta de cuatro preguntas para detección de PTSD. Se ofreció y proporciono remisión a MHT.

Note: Paper presented in General Research Competition at the annual congress of Panamerican Trauma Society, Panama City, Panama, November 2015. 
Resultados: Se evaluaron ciento veinte y seis pacientes. Sesenta y cuatro (51\%) pacientes se llegó a las 4 a 6 semanas después del alta y $60(48 \%)$ completaron la herramienta completa de 4 ítems. Cincuenta (78\%) tenido GSW, 7 (11\%) tenía heridas de arma blanca, y 7 (11\%) tenían asalto. Sesenta y dos por ciento informó que experimentaron al menos un importante síntoma de trastorno de estrés postraumático, y el $52 \%$ experimentaron $>2$ síntomas principales. Ochenta y siete por ciento de los pacientes que desarrollaron síntomas del PTSD negaron referencias pre-descarga. Los pacientes postdescarga, con al menos un síntoma de PTSD (37) solicitaron MHT a una tasa significativamente más alta que los que no tienen síntomas $(23 ; p=<0,0001)$. Los pacientes con remisión de 3 a 4 síntomas solicitaron información a una velocidad mayor que aquellos con 0 a 2 síntomas ( $p \leq 0,0001)$.

Conclusión: Los pacientes violentamente heridos están en riesgo de la desarrollo de los síntomas de PTSD después del alta. Los centros de trauma tienen una oportunidad única para poner en práctica la detección del PTSD, seguimiento después del alta y referencia para tener efecto y cambiar para esta población en riesgo.

Palavras chave: Centro de trauma, Lesión violenta, Prevalencia, Salud mental, Trastorno de estrés postraumático.

\section{INTRODUCTION}

Each year in the United States, over 2 million individuals experience non-fatal injuries related to violence. ${ }^{1}$ In addition to potential long-term physical impairment, injured patients are at risk for developing psychological symptoms as well, including post-traumatic stress disorder (PTSD). Post-traumatic stress disorder is characterized by four distinct clusters of psychological symptoms including re-experiencing, avoidance, negative cognitions and mood, and arousal. ${ }^{2}$ Individuals meet diagnostic criteria if symptoms have occurred for at least 4 weeks following an exposure to trauma and are accompanied by significant impairment in one's ability to function in important areas of daily living. ${ }^{2}$ Lifetime prevalence of PTSD in the United States is estimated at $8 \% .^{3}$ Individuals who have been violently injured experience PTSD at a much higher estimated rate at $20 \%$ or higher. ${ }^{4-6}$ This is particular significance for urban trauma centers who treat a high volume of violently injured patients.

We sought to evaluate the prevalence of posttraumatic stress symptoms in violently injured patients discharged from a level 1 trauma center. Additionally, we sought to evaluate the need for and receptiveness to referrals for mental healthcare for patients at risks for PTSD. The risk of developing PTSD post-violent injury is high, yet previous studies have demonstrated that follow-up mental healthcare service utilization was low and have suggested that screening along with pyschoeducation regarding post-traumatic stress responses may lead to early intervention and more positive outcomes in multiple domains. ${ }^{78}$

\section{METHODS}

Between January 1, 2013 and December 31, 2013, we conducted a quality improvement study. Violently injured patients were provided education on PTSD symptoms and typical responses to traumatic injury. Patients were also offered a list of mental health treatment resources in their localities along with instructions on how to access treatment. Services were provided by a master's trained clinical social worker while the patient was in the hospital. Patients in police custody, with self-inflicted injuries, with injuries related to domestic violence, or who were non-English speaking were offered other services and were not included in the quality improvement (QI) analysis. At 4 to 6 weeks post-discharge, patients were contacted by their hospital social worker who administered the validated four item PTSD screening tool PC-PTSD. The social worker discussed responses to the screening tool, offered referrals to mental health treatment, and reiterated the process for accessing mental health crisis services if requested.

\section{RESULTS}

During the quality improvement study period, 3,525 patients were admitted to a level 1 urban trauma center, of which $560(18 \%)$ suffered a violent injury. Two hundred and seven $(37 \%)$ were ineligible based on exclusion criteria. One hundred and twenty-six (23\%) violently injured trauma patients were provided services while inpatient. Sixty-four (51\%) patients were contacted by phone at 4 to 6 weeks post-discharge by phone, and participated in the PC-PTSD assessment. Fifty (78\%) had GSW, 7 (11\%) had stab wounds, and 7 (11\%) had assault. Fifty-eight $(91 \%)$ were males and $6(9 \%)$ were females. Forty $(62 \%)$ reported experiencing at least one symptom of PTSD, and $33(52 \%)$ experienced $>2$ symptoms. Thirtyfive ( $87 \%$ ) of patients who developed symptoms of PTSD refused referrals pre-discharge. Post-discharge, patients with at least one PTSD symptom requested referrals for mental health treatment at a significantly higher rate than those without symptoms (37 vs 23; $\mathrm{p} \leq 0.0001$ ). Patients with 3 to 4 symptoms requested referral information at a higher rate than those with 0 to 2 symptoms ( $\mathrm{p} \leq 0.0001$ ).

\section{DISCUSSION}

The development of PTSD in injured populations is associated with a variety of risk factors, negative outcomes, and co-occurring mental health disorders. Traumatically injured individuals who develop PTSD are less likely to return to work within 12 months of injury than their counterparts who do not develop PTSD. 9 Civilians with PTSD are also more likely to be involved in 
the criminal justice system with charges related to violent offenses. ${ }^{10}$ Many violently injured patients will not meet the full criteria for PTSD, yet experiencing even some symptoms of post-traumatic stress can lead to negative outcomes. Previous studies have demonstrated that PTSD symptoms related to violent injury have resulted in increased levels of substance use and in weapon carrying. ${ }^{11}$ Post-traumatic stress disorder symptomology post-violent injury is also associated with a lower quality of life (QoL) within multiple domains including physical health and relationships with others. ${ }^{12}$

Violent injury is a risk factor for the development of PTSD. This is of particular significance for urban trauma hospitals in United States with high exposure to penetrating injuries, mostly due to violence. In our level 1 trauma center, violent injuries represents $16 \%$ of our admissions who could be at risk for PTSD. We carried out this quality improvement study to evaluate prevalence of PTSD symptoms post-discharge in patients who had been hospitalized for violent injury. Our data adds to increasing literature demonstrating the high prevalence of PTSD symptoms in this patient population. Of interest, our data demonstrates that, while inpatient, the majority of patients did not anticipate the need for further mental health follow-up for PTSD post-discharge. It is possible that, while hospitalized, patients were more focused on resources needed to heal their physical injuries and were not focused on psychological recovery. Most patients were receptive to the information about PTSD that was provided to them while inpatient but did not think that they would need it.

Multiple screening and assessment tools currently exist for PTSD and trauma exposure. The primary carePTSD screen (PC-PTSD) is a four item tool designed to screen for PTSD in the primary care setting, with each question corresponding to one of the symptom clusters within the PTSD diagnosis (cite). Its brevity, sensitivity, specificity, and efficiency have made it a practical and effective tool used in both the primary care and acute care settings. ${ }^{13,14}$ This screening tool does not diagnose PTSD, but screens for patients at high risk for having or developing the disorder and serves as a point of referral for further services. Using a binary (yes/no) response system, the PC-PTSD screen is considered positive if three or more symptoms are reported. This scale does not capture symptom severity. Patients exhibiting even one positive response may be in need of further assessment and services. Only through post-discharge screening during a time frame when symptoms of PTSD had either begun to emerge or had persisted in severity were we able to capture this need and provide additional services.
We have demonstrated that patients hospitalized for violent injury do not anticipate the development of PTSD symptoms. The implementation of follow-up phone calls by hospital staff in order to assess for symptoms and provide additional resources is important. It is unknown, however, if these patients with PTSD symptoms who requested additional referral information succeeded in accessing care. Additional follow-up with these patients to determine both ongoing mental health needs and service utilization are areas of potential future study. Limitations of the quality improvement study include a small initial sample size from a single institution. Additionally, almost half of the patients were lost to follow-up. This is consistent from our previous study on the same patients population. ${ }^{15}$ A multi-institutional study would be important to further this work. Lastly, the current QI study did not attempt to link injury severity with the incidence of PTSD symptoms, which has been addressed in other studies. Zatzick et al, noted that injury type and increasing injury severity were not associated with higher levels of PTSD. ${ }^{16}$ Other factors, including higher number of previous trauma, stimulant intoxication and female gender, were associated with higher levels of symptoms in the year after the injury. ${ }^{16}$

\section{CONCLUSION}

Violently injured patients are at risk for the development of PTSD symptoms post-discharge. Trauma centers have a unique opportunity to implement PTSD screening, referral and post-discharge follow-up to effect change for this at-risk population. This is particularly important for trauma center verification by the American College of Surgeons, where PTSD screening is now mandated for level 1 trauma center verification.

\section{REFERENCES}

1. Centers for Disease Control and Prevention. Web-based Injury Statistics Query and Reporting System [Online]. (2003). National Center for Injury Prevention and Control, Centers for Disease Control and Prevention (producer). Available at: URL: www.cdc.gov/ncipc/wisqars. [2014 September 25].

2. American Psychiatric Association. Diagnostic and statistical manual of mental disorders. 5th ed. Washington, DC: Author 2013.

3. Kessler R, Sonnega A, Bromet E, Hughes M, Christopher B, Nelson C. Posttraumatic stress disorder in the national comorbidity survey. Arch Gen Psychiatry 1995;52(12): 1048-1060.

4. Johanson V, Wahl A. Prevalence and predictors of posttraumatic stress disorder in physically injured victims of non-domestic violence. Soc Psychiatry Pychiatr Epidemiol 2007;42(7):583-593.

5. Warren A, Foreman M, Bennett M, Petrey L, Reynolds M, Patel S, Roden-Forman K. Posttraumatic stress disorder following traumatic injury at 6 months: Associations with 
alcohol use and depression. J Trauma Acute Care Surg 2014; 76(2):517-522.

6. Zatzick DF, Rivara FP, Nathens AB, Jurkovich GJ, Wang J, Fan MY, Russo J, Salkever DS, Mackenzie EJ. A nationwide US study of posttraumatic stress after hospitalization for physical injury. Psycol Med 2007;37(10):1469-1480.

7. Wong E, Kennedy D, Marshall G, Gaillot S. Making sense of posttraumatic stress disorder: Illness perceptions among traumatic injury survivors. Pyschological Trauma: Theory, Research, Practice and Policy 2011;3(1):67-76.

8. Jaycox L, Marshall GN, Schell T. Use of mental health services by men injured through community violence. Psychiatric Services 2004;55(4):415-420.

9. Zatzick D1, Jurkovich GJ, Rivara FP, Wang J, Fan MY, Joesch J, Mackenzie E. A national US study of posttraumatic stress disorder, depression, and work and functional outcomes after hospitalization for traumatic injury. Ann Surg 2008 Sep; 248(3):429-437.

10. Donley S, Habib L, Jovanovic T, Kamkwalala A, Evces M, Egan G, Bradley B, Ressler K. Civilian PTSD symptoms and risk for involvement in the criminal justice system. J Am Acad Psychiatry Law 2012;40(4):522-529.

11. Corbin T, Purtle J, Rich J, Rich L, Adams E, Yea G, Bloom S. The prevalence of trauma and childhood adversity in an urban, hospital-based violence intervention program. J Healthcare Poor Underserved 2013;24(3):1021-1030.

12. Johansen V, Wahl A, Eilertsen D, Weisaeth L, Hanestad B. The predictive value of post-traumatic stress disorder symptoms for quality of life: a longitudinal study of physically injured victims of non-domestic violence. Health and Quality of Life Outcomes 2007;5(26):1-11.

13. Hanley J, deRoon-Cassini T, Brasel K. Efficiency of a fouritem posttraumatic stress disorder screen in trauma patients. J Trauma Acute Care Surg 2013;75(4):722-727.

14. Prins A, Ouimette P, Kimerling R, Cameron R, Hugelshofer D, Shaw-Hegwer J, Thrailkill A, Gusman F, Sheikj J. The primary care PTSD screen: development and operating characteristics. Primary Care Psychiatry 2003;9(1)9-14.

15. Aboutanos MB, Jordan A, Cohen RD, Foster RL, Goodman K, Halfond R, Poindexter R, Charles R, Smith S, Wolfe L, Hogue B, Ivatury $R$. Brief violence interventions with community case management services are effective for high-risk trauma patients. J Trauma-Injury Infection and Critical Care 2011; 71(1):228-237.

16. Zatzick D, Kang SM, Müller HG, Russo JE, Rivara FP, Katon W, Jurkovich GJ, Roy-Byrne P. Predicting posttraumatic distress in hospitalized trauma survivors with acute injuries. Am J Psychiatry 2002;159(6):941-946. 


\section{Post-traumatic Stress Symptoms in a Violently Injured Civilian Population: A Need for Hospital Identification and Resources}

I read with great interest the article by Jordan et al. ${ }^{1}$ The authors present a descriptive study of their program to screen patients who were victims of violence for Post-traumatic stress disorder (PTSD). They focused on those patients who were victims of penetrating trauma or assaults. They excluded those with self-inflicted injuries, injuries related to domestic violence or those who were non-English speaking. They followed these patients while in-patients and then followed up with them 4 to 6 weeks post-discharge. They found that $62 \%$ of the patients suffered from at least one symptom of PTSD and $52 \%$ experienced $\geq 2$ symptoms. Interestingly, $87 \%$ of patients who developed symptoms of PTSD refused referrals for mental health management. They were able to follow-up on approximately $50 \%$ of the patients post-discharge and the rate of accepting mental health management help significantly increased, particularly in those with $\geq 2$ symptoms. They conclude that the number of those with PTSD symptoms is high in those who suffer violent trauma and the acceptance of help significantly increases post-discharge.

Violent crimes account for over 2 million injuries annually in the United States. The incidence of PTSD in these patients is unclear but ranges from 30 to $80 \% .^{2}$ This had led the American College of Surgeons to mandate PTSD screening programs in level 1 trauma centers in the USA. However, it is unclear how effective these programs are in terms of minimizing the resulting effects of PTSD. Despite greater emphasis on PTSD by the department of defense and veterans administration there remains a gap in care for those with PTSD in both the military and civilian sectors. Once the screening is done and the patients identified and referrals made it remains unclear if these interventions are helping. This study addresses the at risk population but, as the authors suggest, does not ensure that the interventions proposed for screening actually lead to improved outcomes, i.e. readmissions, suicide, return to work, etc.

In addition, I would encourage the authors and others interested in this topic to include those with violent domestic assaults. When reviewing those from the Vietnam era there was a 33\% incidence of recurrent violence in those with PTSD vs $13.5 \%$ in those without PTSD. ${ }^{3}$ This highlights the cycle of violence in those with symptoms of PTSD. The authors take the first step in understanding how an intervention may prevent this cycle of violence by defining the at risk group.

I look forward to future studies from this group regarding how their interventions actually affect the quality of life or the cycle of violence for those with PTSD. I would encourage them to include those who are victims of domestic violence. They offer an interesting insight into the prevalence of PTSD in our trauma population. As a trauma community, it is our responsibility to ensure that we meet the mental, as well as, physical needs of our patients. The problem of violence and subsequent PTSD is not a unique problem. However, there may be cultural differences and solutions in our global community that require further investigation.

\section{REFERENCES}

1. Jordan A, Goldberg S, Bivins J, Hogue B, Wolfe L, Aboutanos M. Post-traumatic stress symptoms in a violently injured civilian population: a need for hospital identification and resources. Panamerican J Trauma Emerg Surg Critical Care 2015; XXXXX

2. Brewin CR, Andrews B, Valentine JD. Meta-analysis of risk factors for post-traumatic stress disorder in trauma-exposed adults. J Consulting and Clinical Psychology 2000;68(5):748-766.

3. Jordan KB, Marmar CR, Fairbank JA, et al. Problems in families of male Vietnam Veterans with post-traumatic stress disorder. J Consulting and Clinical Psychology 1992;60(6):916-926.

Marc de Moya MD FACS Massachusetts General Hospital Harvard Medical School Division of Trauma

Boston, Massachusetts, USA 